\title{
Oil type and temperature dependent biodegradation dynamics - Combining chemical and microbial community data through multivariate analysis
}

Deni Ribicic ${ }^{1,2^{*}}$, Kelly Marie McFarlin ${ }^{1}$, Roman Netzer ${ }^{1}$, Odd Gunnar Brakstad ${ }^{1}$, Anika Winkler ${ }^{3}$, Mimmi Throne-Holst ${ }^{1}$ and Trond Røvik Størseth ${ }^{1}$

\begin{abstract}
Background: This study investigates a comparative multivariate approach for studying the biodegradation of chemically dispersed oil. The rationale for this approach lies in the inherent complexity of the data and challenges associated with comparing multiple experiments with inconsistent sampling points, with respect to inferring correlations and visualizing multiple datasets with numerous variables. We aim to identify novel correlations among microbial community composition, the chemical change of individual petroleum hydrocarbons, oil type and temperature by creating modelled datasets from inconsistent sampling time points. Four different incubation experiments were conducted with freshly collected Norwegian seawater and either Grane and Troll oil dispersed with Corexit 9500. Incubations were conducted at two different temperatures $\left(5^{\circ} \mathrm{C}\right.$ and $\left.13^{\circ} \mathrm{C}\right)$ over a period of 64 days.

Results: PCA analysis of modelled chemical datasets and calculated half-lives revealed differences in the biodegradation of individual hydrocarbons among temperatures and oil types. At $5{ }^{\circ} \mathrm{C}$, most $n$-alkanes biodegraded faster in heavy Grane oil compared to light Troll oil. PCA analysis of modelled microbial community datasets reveal differences between temperature and oil type, especially at low temperature. For both oils, Colwelliaceae and Oceanospirillaceae were more prominent in the colder incubation $\left(5^{\circ} \mathrm{C}\right)$ than the warmer $\left(13^{\circ} \mathrm{C}\right)$. Overall, Colwelliaceae, Oceanospirillaceae, Flavobacteriaceae, Rhodobacteraceae, Alteromonadaceae and Piscirickettsiaceae consistently dominated the microbial community at both temperatures and in both oil types. Other families known to include oil-degrading bacteria were also identified, such as Alcanivoracaceae, Methylophilaceae,

Sphingomonadaceae and Erythrobacteraceae, but they were all present in dispersed oil incubations at a low abundance $(<1 \%)$.
\end{abstract}

Conclusions: In the current study, our goal was to introduce a comparative multivariate approach for studying the biodegradation of dispersed oil, including curve-fitted models of datasets for a greater data resolution and comparability. By applying these approaches, we have shown how different temperatures and oil types influence the biodegradation of oil in incubations with inconsistent sampling points. Clustering analysis revealed further how temperature and oil type influence single compound depletion and microbial community composition. Finally, correlation analysis of degraders community, with single compound data, revealed complexity beneath usual abundance cut-offs used for microbial community data in biodegradation studies.

\footnotetext{
* Correspondence: deni.ribicic@sintef.no

${ }^{1}$ SINTEF Ocean, Environment and New Resources, Brattørkaia 17C, 7010

Trondheim, Norway

${ }^{2}$ Department Clinical and Molecular Medicine, The Norwegian University of

Science and Technology, 7491 Trondheim, Norway

Full list of author information is available at the end of the article
}

(c) The Author(s). 2018 Open Access This article is distributed under the terms of the Creative Commons Attribution 4.0 International License (http://creativecommons.org/licenses/by/4.0/), which permits unrestricted use, distribution, and reproduction in any medium, provided you give appropriate credit to the original author(s) and the source, provide a link to the Creative Commons license, and indicate if changes were made. The Creative Commons Public Domain Dedication waiver (http://creativecommons.org/publicdomain/zero/1.0/) applies to the data made available in this article, unless otherwise stated. 


\section{Background}

Marine oil biodegradation is influenced by a variety of factors, both environmental (e.g. microbial composition, nutrient and oxygen concentrations, seawater temperature, and the presence of ice) and oil-related (e.g. oil type, concentration, and weathering). The majority of oil-biodegradation studies have focused on environmental effects, while the influence of oil type on biodegradation has not received as much attention. Environmental factors and oil properties do not affect oil-biodegradation separately, but have combined effects as environmental factors, such as temperature and wind, can have profound effects on the property of oil over time. To truly understand how environmental factors influence oil-biodegradation, it is important to study and compare many variables at once. Therefore, it becomes important to combine environmental factors with the physicochemical properties of oil when studying their effect on oil-biodegradation.

Temperature, and thus thermodynamics, influences all aspects of life [1] and has been shown to play a predominant role in oil biodegradation $[2,3]$. Temperature influences the activity of microbial enzymes and the physicochemical characteristics of the oil. In general, biochemical reactions exponentially decrease with decreasing temperature but microorganisms have adapted mechanisms to thrive at low temperatures [4]. Psychrophilic microorganisms overcome constraints imposed by low temperatures by producing cold-adapted enzymes, which allow them to function more efficiently at low temperatures compared to their mesophilic counterparts $[4,5]$. The ability of temperature to influence microbial community structure is well known [6], but field studies strongly suggest that oil-degrading potential is not influenced by statistical differences in microbial community structure. For example, the genetic potential to biodegrade oil was found to be independent of community structure in offshore Arctic seawater [7]. In addition, similar oil-degrading genes have been found in cold and temperate environments $[7,8]$. The ubiquity of oil-degrading microorganisms highlights the abundance of genetic transfer and the importance of molecular analyses.

The effects of temperature on the physicochemical properties of oil is likely to have a stronger influence on oil-biodegradation than would the influence of microbial community structure. Declining temperatures increase oil viscosity, while decreasing rates of solubility, dissolution, and volatilization. These processes decrease the bioavailability of oil compounds to degradative microorganisms and may prolong the presence of toxic aromatic hydrocarbons in cold environments [2, 9].

Characterizing the biodegradation of oil through detailed chemical and microbial analysis is challenging due to the extremely large data sets produced with high throughput technology. Such large data sets are even responsible for the creation of a new field of study (i.e. bioinformatics), which develops computational tools to understand biological data [10]. The inherent complexity of these data represents challenges, both with respect to inferring correlations and the visualization of multiple datasets with hundreds to thousands of components (i.e. oil compounds or bacterial genes) and numerous environmental variables. The complexity of oil analysis is often alleviated by grouping compounds into classes [11]; however, this approach should be used with caution as grouping may mask trends in single component degradation. For microbial community data, a typical approach is to focus on the most abundant species, as they are expected to have the greatest effect on biodegradation.

Here, we demonstrate how simple statistical tools can be utilized to analyze complex data sets. Common statistical analyses, including ordinations and grouping classifications, can infer differences and allow the visualization of patterns. For single variable datasets, principal components analysis (PCA) is one of the most commonly used ordination tools and allows users to reduce the variation between data points while conserving dominant trends [12]. Data generated in such a way allows for direct comparison of one sample with another but limits the user to one variable. Here we use PCA plots and heatmaps to identify relationships describing the biodegradation of Troll and Grane oil at two different temperatures $\left(5{ }^{\circ} \mathrm{C}\right.$ and $\left.13{ }^{\circ} \mathrm{C}\right)$. Another objective of this study is to predict the chemical loss of oil and the microbial community structure at different time points. This predictive analysis may save time and cost by quantitatively predicting oil loss at different temperatures and biodegradation potential in the absence of sampling. Here we compare two incubation studies with different sampling times to demonstrate how a predictive curve-fitted model enables comparisons between different treatments at the same time point in the absence of uniform sample collection.

\section{Methods}

\section{Experiment setup}

Two fresh crude oils (Grane and Troll), with different chemical properties, were chemically dispersed into freshly collected seawater. Mesocosms were incubated for 30-64 days in a carousel system at two temperatures $\left(5{ }^{\circ} \mathrm{C}\right.$ and $\left.13{ }^{\circ} \mathrm{C}\right)$. Therefore, four different incubation experiments (two oils at two temperatures) were conducted and were sampled at different time points (Fig. 1 and Additional file 1: Table S1). At each time point (day $3,6,7,9,13,14,16,21,30$ and 64) samples were collected and analyzed for chemical loss and microbial community structure. 


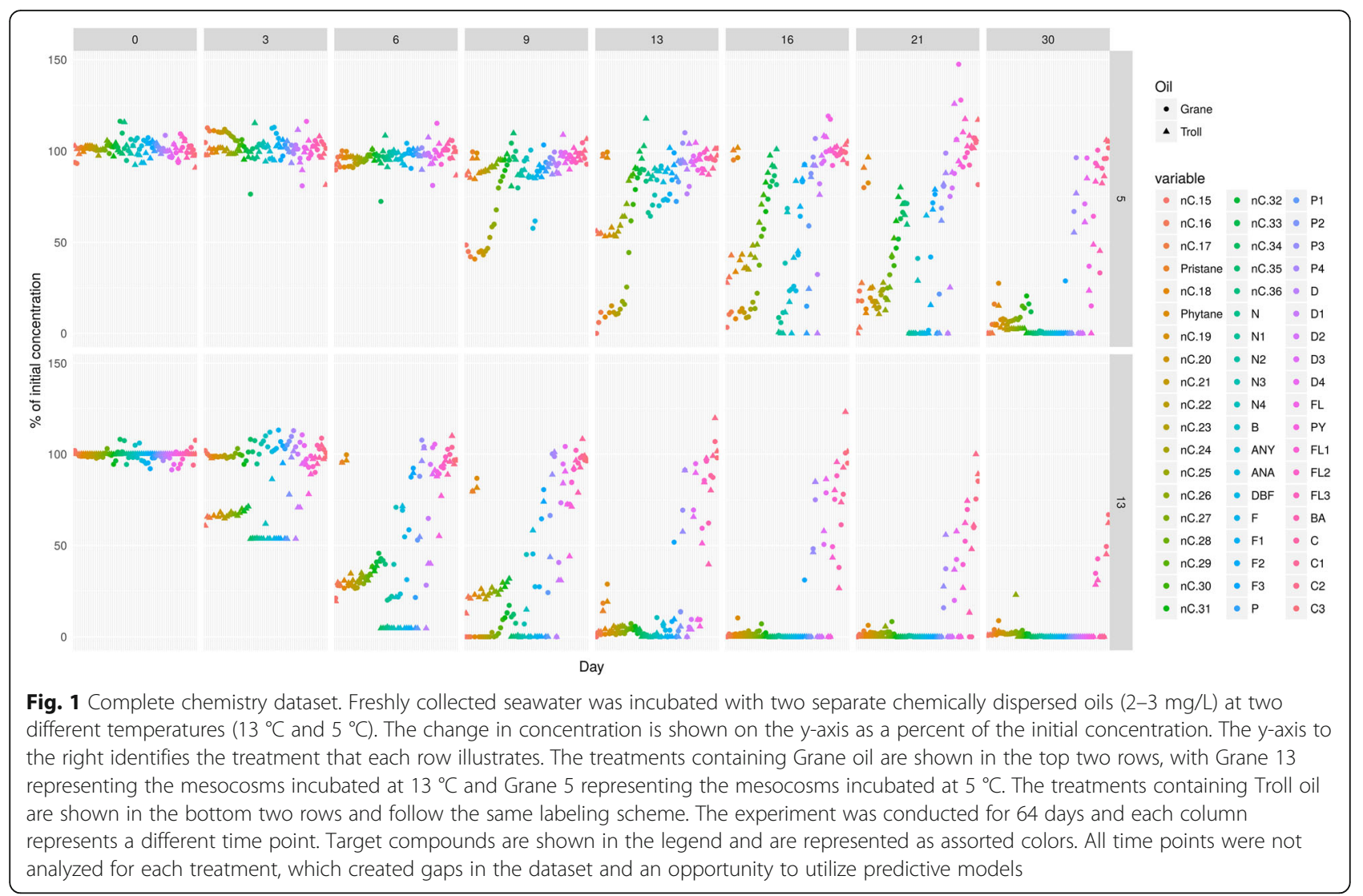

\section{Oil, dispersant and seawater}

Troll (naphthenic oil, 2007-0087) and Grane (asphaltenic oil, 2012-0331) were pre-heated at $50{ }^{\circ} \mathrm{C}$ for $30 \mathrm{~min}$ to melt the wax in the oil caused by cold storage, and then cooled to room temperature. Physicochemical characteristics of the two oils are shown in Table 1. The oils were premixed with Corexit 9500 (DOR 1:100) before preparing the oil/seawater dispersions (see next section). Seawater was collected via a pipeline system at $80 \mathrm{~m}$ depth (below thermocline, salinity $34 \%$, $5.9{ }^{\circ} \mathrm{C}$ ) in a Norwegian fjord (Trondheimsfjord; $63^{\circ} 26^{\prime} \mathrm{N}, 10^{\circ} 23^{\prime} \mathrm{E}$ ), outside the harbour area of Trondheim and was acclimated for two days at $5{ }^{\circ} \mathrm{C}$ and $13{ }^{\circ} \mathrm{C}$ before start of the biodegradation experiment.

\section{Biodegradation experiment}

Stock dispersion solutions were created with a droplet generator system [13] which ensured $10 \mu \mathrm{m}$ oil droplets and an oil concentration of $200 \mathrm{mg} / \mathrm{L}$. Based on oil droplet concentration measurements (Coulter Counter; see next section), each stock dispersion was diluted in natural unfiltered seawater (previously acclimated at $5^{\circ}$ $\mathrm{C}$ and $13{ }^{\circ} \mathrm{C}$ ) to reach a final nominal concentration of 2-3 mg/L oil droplets. Negative controls contained sterilized $\left(\mathrm{HgCl}_{2}\right)$ seawater. Additional nutrients were not added to the natural seawater as previous studies have shown that these low oil concentrations do not produce limiting conditions $[14,15]$. The seawater dispersions were distributed in baked $\left(450{ }^{\circ} \mathrm{C}\right)$ and autoclaved flasks (2 L; Schott), and were filled and capped without headspace or air bubbles. Flasks were mounted on a carousel system with slow continuous rotation $(0.75 \mathrm{rpm})$, as previously described [13]. The carousels were maintained at $5{ }^{\circ} \mathrm{C}$ and $13{ }^{\circ} \mathrm{C}$ for 64 days in the dark, and flasks were sacrificed in replicates for analyses after 30 min incubation. Sampling regimes and replicates are described in detail in Additional file 1: Table S1. In addition to the sterilized controls, seawater controls containing

Table 1 Properties of Troll and Grane oil

\begin{tabular}{lllllll}
\hline Oil & Category & $\begin{array}{l}\text { Viscosity } \\
\left(\mathrm{mPas} 13^{\circ} \mathrm{C}\right)\end{array}$ & $\begin{array}{l}\text { Density } \\
(\mathrm{g} / \mathrm{cm} 3)\end{array}$ & $\begin{array}{l}\text { Pour point } \\
\left({ }^{\circ} \mathrm{C}\right)\end{array}$ & $\begin{array}{l}\text { Wax } \\
(\text { vol\%) }\end{array}$ & $\begin{array}{l}\text { Asphaltene } \\
(\mathrm{wt} \%)\end{array}$ \\
\hline Troll & Naphthenic & 27 & 0.900 & -18 & 2.0 & 0.20 \\
Grane & Asphaltenic & 667 & 0.941 & -18 & 1.5 & 1.40 \\
\hline
\end{tabular}


unfiltered seawater without oil dispersion were incubated at the same conditions.

\section{Analyses}

\section{Oil droplet size and concentrations}

Concentrations and size distributions of oil droplets were determined by Coulter Counter measurements (Beckman Multisizer 4; Beckman Coulter Inc., Brea, CA, U.S.A), fitted with $280 \mu \mathrm{m}$ aperture. This apparatus was used for measurements of droplets within a diameter range $5.6-100 \mu \mathrm{m}$. Sterile-filtered $(0.22 \mu \mathrm{m})$ seawater was used as electrolyte in the Coulter Counter. Droplet concentrations were determined from volume concentrations $\left(\mu \mathrm{m}^{3} / \mathrm{ml}\right)$ and recalculated $(\mathrm{mg} / \mathrm{L})$ based on the density of the fresh oil.

\section{Chemical analyses}

Alliquots of dispersed oil treatments dispersions were solvent-solvent extracted (dichloromethane, DCM) and analysed by gas chromatographic methods. Flasks were rinsed with DCM after removal of dispersions to extract oil attached to the glass walls. Extracts of dispersions and glass walls were pooled. Total extractable organic carbon (TEOC) was analysed by GC-FID, while quantification of 57 individual targeted compounds $(n \mathrm{C} 10-n \mathrm{C} 36$ n-alkanes, decalins, phenols, 2- to 5-ring polycyclic aromatic hydrocarbons (PAH) and $17 \alpha(\mathrm{H}), 21 \beta(\mathrm{H})$-Hopane) was performed by GC-MS analysis, as previously described [16]. In the GC-MS analysis, response values for individual target analytes were determined and based on a signal-to-noise ratio $>10$. The lower limit of detections (LOD) varied from 0.001 to $0.01 \mu \mathrm{g} / \mathrm{L}$ for individual oil compounds. Target analytes were normalized against $17 \alpha(\mathrm{H}), 21 \beta(\mathrm{H})$-Hopane $[17,18]$ and sterile controls. Concentrations are reported as a percent of the initial oil concentration.

\section{DNA extraction and 16S rRNA gene data processing}

Seawater samples $(\sim 500 \mathrm{ml}$, with and without oil and oil dispersions) were filtered through $0.22 \mu \mathrm{m}$ filters (MilliporeSigma Durapore ${ }^{\circledR}$, Merck, NJ, USA). Genomic DNA was extracted from the filters using a FastDNA Spin kit for soil (MP Biomedicals, CA, USA) according to the manufacturer's instructions. Genomic DNA concentrations were quantified using Qubit 3.0 (ThermoFisher Scientific, MA, USA) with a dsDNA High Sensitivity kit (ThermoFisher Scientific, MA, USA).

Amplicons of $16 \mathrm{~S}$ rRNA were generated according to Illumina's "16S Metagenomic Sequencing Library Preparation" protocol using the S-D-bact-0341-b-S-17 and S-bact-0785-a-A-21 primer set [19]. Amplicons obtained by PCR were purified using magnetic beads (Agencourt Amoure XP Beads). Libraries were quantified using Quant iT Picogreen Dye and the Fragment Analyzer
(Advanced Analytical) on Agilent's Bioanalyzer. All amplicons were pooled equimolar and then sequenced paired-end on the Illumina MiSeq platform, $2 \times 300 \mathrm{nt}$, following manufacturer instructions.

Raw pair-end reads were assembled with fastq-join using QIIME 1.9.1 [20]. Assembled sequences were demultiplexed and quality filtered to remove low quality reads (Phred score < 20; -q 19). UCHIME was employed for chimera detection on assembled quality filtered reads [21]. Operational taxonomic units (OTUs) were determined by clustering assembled sequences on 97\% nucleotide identity using UCLUST [22] with open reference clustering option. Representative sequences were aligned with PyNAST [23] and taxonomy assignment was performed with RDP classifier [24] based on SILVA-123 database [19]. QIIME pipeline generated biome file was used as input for $\mathrm{R}$ Phyloseq package v.1.12.2 [25] for beta diversity analysis and generating community composition figures. Only sequences that had mean relative abundances $(n=3)>1 \%$ of the total community relative abundance, at least at one time point, were included in the graphical output for the community composition.

\section{Multivariate data analysis}

Total microbial community data were agglomerated to the family level, replicates were averaged and relative abundances were calculated with the Phyloseq package [25]. The chemistry data were normalized to $17 \alpha(\mathrm{H}), 21 \beta(\mathrm{H})$-Hopane and compared to the sterile controls to describe the degradation of each component as a percentage of the starting concentration at each timepoint in the absence of abiotic losses.

The time series for each oil and temperature contained different sampling points (Fig. 1). To obtain identical time points for better comparison, a local polynomial regression was fitted to the data for each individual (each component/species for each temperature and each oil) time series using the loess function in the $R$ stats-package (v.3.2.2). The resulting line fit (loess-model) was used to interpolate the \% loss of oil components and the relative abundance of bacterial families at days $0,3,6,9,13,16,21$ and 30. For the modelled data, the minimum value was set to zero to account for any sub-zero predictions. For the microbial data, this was achieved by normalizing the data to unity (sum all abundances $=1$ ). The modelled time series were then used for PCA analysis and for describing compositional changes over time.

For total microbial community data, PCA was performed using sparse PCA from the mixOmics-package (spca, on centered and scaled data using 3 components) [26]. For the chemistry data, prcomp (centered and scaled) from the base stats package was used. After 
generating the PCA models, the scores were extracted, and plots were generated with ggplot2. For the modelled microbial data, a smoothed loess function was added to the basic point-plot (geom_point) using stat_smooth for each sequential group of four time points. For the modelled chemistry data, a single smoothed function was added which was based on all four time series using geom_smooth defaults (0.95 confidence interval, loess function). Regressions using pls were built via Clustered Image Map (CIM) function (within mixOmics package) with chemistry data as xblock and microbial community data as yblock to study correlations and clustering between datasets.

\section{Results}

\section{Chemical analyses}

The chemistry dataset gathered in this study characterized 57 oil components from two oils at two temperatures over 64 days with different sampling time points (Fig. 1). Biodegradation half-lives are presented in Additional file 2: Table S2. A PCA score plot was generated to condense the complex data and enable analysis among oil types and temperatures. The PCA plot of the chemical profiles (GC-MS and GC-FID results) within individual treatment replicates illustrated a similar trajectory among oil types and temperatures, but clustering of experimental replicates incubated with different oils and different temperatures revealed several trends in alkanes and aromatic biodegradation among the four experiments (Fig. 2). Patterns of biodegradation can be compared among treatments, as the PAH/alkane ratio is represented in $\mathrm{PC} 2$ and total oil biodegradation represented in PC1. As time points increased along the PC2 axis, alkane biodegradation surpassed $\mathrm{PAH}$ biodegradation and the slope of the curve became positive. The top of the bell curve (the PC2 maximum) illustrates when the loss of alkanes and PAHs was most similar. As the experiments proceeded, alkanes were depleted, and the loss of PAHs exceed that of alkanes and thus the slope of the curve becomes negative. In Grane and Troll incubations at $13{ }^{\circ} \mathrm{C}$, the largest separation on the $\mathrm{PC} 1$ axis was observed between day 0-6 and day 7, with day 0-6 incubations all clustering together (Fig. 2). Another strong cluster between Grane and Troll incubations formed after the PC2 maximum, where day $30\left(5{ }^{\circ} \mathrm{C}\right)$ and $14\left(13^{\circ} \mathrm{C}\right)$ were found in close proximity (Fig. 2).

When the composition of individual hydrocarbons were compared between the two oils at the same time point, the two oils grouped separately at $5{ }^{\circ} \mathrm{C}$ but not $13{ }^{\circ} \mathrm{C}$ (Fig. 2). The biodegradation of Grane at day $6\left(5^{\circ}\right.$ $\mathrm{C}$ and $13{ }^{\circ} \mathrm{C}$ ) clustered with the biodegradation of Troll at day $9\left(5^{\circ} \mathrm{C}\right)$, while day $9\left(\right.$ Grane oil at $\left.5{ }^{\circ} \mathrm{C}\right)$ and day 13 (Troll oil at $5{ }^{\circ} \mathrm{C}$ ) clustered together. Further along the $\mathrm{PC} 1$ axis, day 13 (Grane oil at $5{ }^{\circ} \mathrm{C}$ ) and day 16 (Troll oil at $5{ }^{\circ} \mathrm{C}$ ) clustered together (Fig. 2). Day 16 (dispersed Grane oil at $5{ }^{\circ} \mathrm{C}$ ) and day 7 (dispersed Grane and Troll at $13{ }^{\circ} \mathrm{C}$ ) dominated the top of the bell curve, where the slope of the line approaches 1 and changes among alkanes and PAHs are most similar. After the apex, day 30 (both oils at $5{ }^{\circ} \mathrm{C}$ ) was grouped with day 14 (both oils at $13^{\circ} \mathrm{C}$ ) (Fig. 2).

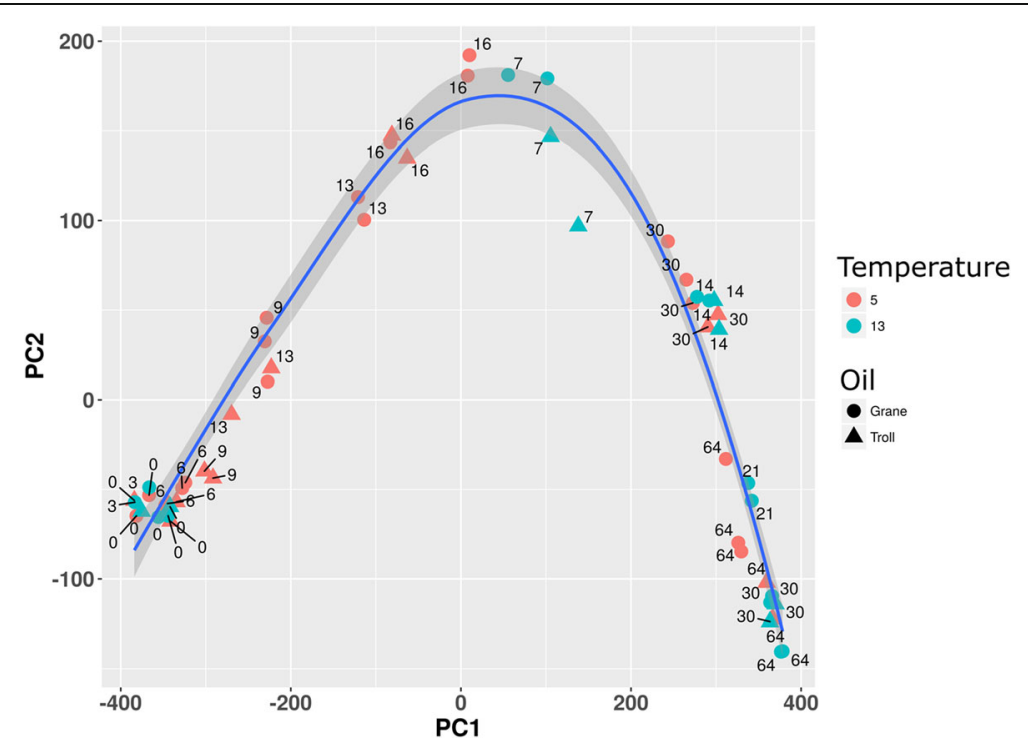

Fig. 2 PCA of the chemical profile of chemically dispersed Grane and Troll oil incubated with seawater at $5{ }^{\circ} \mathrm{C}$ and $13^{\circ} \mathrm{C}$. Each flask is represented as either a circle (Grane oil) or a triangle (Troll oil), and each symbol represents the composition of 57 individual targeted compounds normalized to hopane at that specific time point. Modelled data are present in the figure alongside experimental data to statically analyse the complete data set. Red symbols indicate an incubation temperature of $5^{\circ} \mathrm{C}$ and blue symbols indicate an incubation temperature of $13^{\circ} \mathrm{C} .83 .6$ and $8.3 \%$ of variations are explained with $\mathrm{PC} 1$ and $\mathrm{PC} 2$, respectively 


\section{Microbial community analysis}

Modeled timeseries data can predict microbial community structure in Troll and Grane oil dispersions at the different temperatures. The main difference in microbial community structure between $5{ }^{\circ} \mathrm{C}$ and $13{ }^{\circ} \mathrm{C}$ emerged from the relative abundance of the Colwelliaceae family. At the lower temperature $\left(5{ }^{\circ} \mathrm{C}\right)$, Colwelliaceae increased in abundance at day 3 in both oils (by $22 \%$ ) compared to the unamended control. After day 6, Colwelliaceae exhibited consistently higher abundance in Grane incubations compared to Troll at both temperatures. The relative abundance of Colwelliaceae was slightly greater in Troll dispersions than Grane dispersions at day $6(41 \%$ vs. 34\%), but by day 9 there was more Colwelliaceae in the Grane incubation than the Troll (39\% vs. 35\%) (Fig. 3). By the day 30, abundance of Colwelliaceae decreased substantially (to $\sim 10 \%$ of the total community). At $13{ }^{\circ} \mathrm{C}$, response of Colwelliaceae were rather modest and exhibited maximal values at days 6 and 9 (17.6, 10.8 and 17.5\%, $10.9 \%$ for Grane and Troll, respectively). Colwelliaceae were also prominent at $5{ }^{\circ} \mathrm{C}$ control incubations compared to $13{ }^{\circ} \mathrm{C}$, where after 9 days abundance reached $26.9 \%$ and was maintained until end of experiment (unlike in oil incubations) (Additional file 4: Figure S1). At $13{ }^{\circ} \mathrm{C}$, Colwelliaceae showed rather modest increase in abundance in control incubations $(<10 \%)$, except the sample from incubation day 7 (33.5\%) (Additional file 4: Figure S1).
Oceanospirillaceae responded to both oil dispersions at both temperatures by day 3 (Fig. 3). The relative abundance of Oceanospirillaceae peaked at day 9 in the $13{ }^{\circ} \mathrm{C}$ incubation (38.4 and $22.1 \%$ for Grane and Troll, respectively), and peaked at day 13 in the $5{ }^{\circ} \mathrm{C}$ incubation with Troll (50\%) and at day 16 in the $5{ }^{\circ} \mathrm{C}$ incubation with Grane (51\%) (Fig. 3). Oceanospirillaceae seemed to favor Grane to Troll oil at both temperatures and had higher abundances at $5{ }^{\circ} \mathrm{C}$ compared to $13{ }^{\circ} \mathrm{C}$ (Fig. 3). Oceanospirillaceae were also abundant also in controls, with higher abundances at $5{ }^{\circ} \mathrm{C}$ than $13{ }^{\circ} \mathrm{C}$, but these abundances were low compared to oiled incubations (Additional file 4: Figure S1).

Throughout the incubation, Piscirikettsiaceae and Flavobacteriaceae exhibited different patterns of relative abundance between the two temperatures. The increase in the relative abundance was earlier at $13{ }^{\circ} \mathrm{C}$ than $5{ }^{\circ} \mathrm{C}$ for both families (Fig. 3). It was observed that Piscirickettsiaceae preferred dispersed Troll oil over Grane at both temperatures, and that somewhat higher abundances were achieved at lower temperatures. Piscirickettsiaceae were not observed in control samples. The highest relative abundance of Flavobacteriaceae occurred at $13{ }^{\circ} \mathrm{C}$, with more Flavobacteriaceae responding to dispersed Grane oil (43\%) than Troll $(10 \%)$ at day 30 . At $5{ }^{\circ} \mathrm{C}$ the Flavobacteriaceae only responded after 21 days, and relative abundances reached maximum values at day 30 in both dispersed Grane oil (33\%) and Troll oil (35\%) (Fig. 3). Preferences of Flavobacteriaceae towards a certain oil type or temperature are rather inconclusive based solely on abundances over the

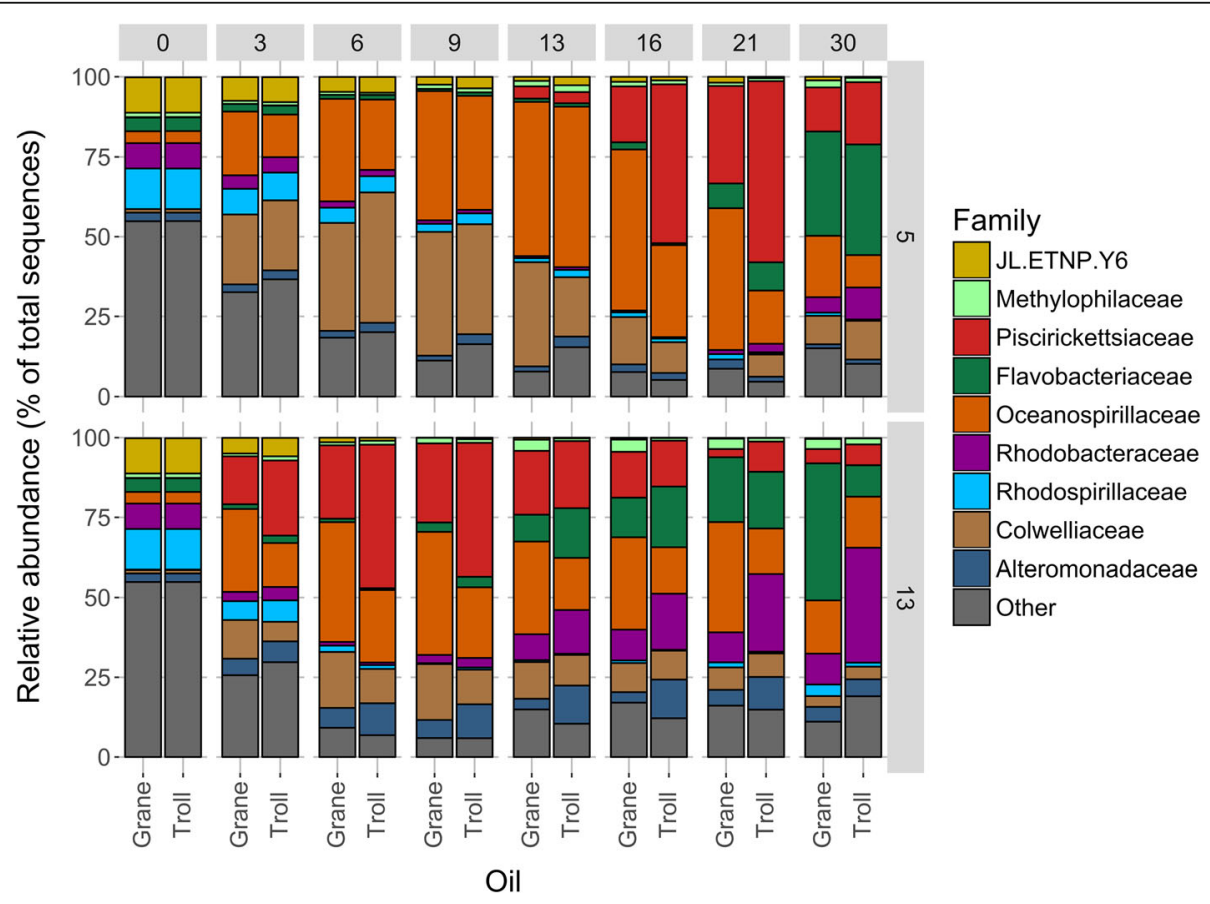

Fig. 3 Mean relative abundance of bacterial families in each treatment from modelled data. Flaks contained seawater incubated with chemically dispersed Grane and Troll oil at 13 and $5{ }^{\circ} \mathrm{C}(2-3 \mathrm{mg} / \mathrm{L}$; DOR 1:100). Figure includes abundances that were $>1 \%$ of the total community 
incubation period. Flavobacteriaceae also increased in control incubations for both temperatures, but only towards the end of experiment (day 64, >15\%), otherwise abundances were $<5 \%$ (Additional file 4: Figure S1).

Alteromonadaceae and Rhodobacteraceae were more dominant at $13{ }^{\circ} \mathrm{C}$ than $5{ }^{\circ} \mathrm{C}$ and seemed to prefer Troll oil over Grane oil at the higher temperature (Fig. 3). The abundance of Alteromonadaceae at $5{ }^{\circ} \mathrm{C}$ did not exceed $3.5 \%$ for any of the oil, but at $13{ }^{\circ} \mathrm{C}$ Alteromonadaceae reached its highest relative abundance between day 1316 with $12 \%$. At $13{ }^{\circ} \mathrm{C}$, Rhodobacteraceae decreased in relative abundance between day 3-9 compared to day 0 ; however, at day 13 Rhodobacteraceae started to increase and reached its highest abundance on day 30 in both oil incubations (36\% in Troll and 10\% in Grane). Alteromonadaceae were not detected in control samples (where the cut-off of $3 \%$ in median abundance was applied), while Rhodobacteraceae maintained the abundance throughout control incubation (<10\%) (Additional file 5: Figure S2).

To identify shifts within the total microbial community in the absence of abundance cut-offs, we performed a PCA analysis of the total sequence data. Patterns along the PC2 axis revealed the influence of temperature on microbial community dynamics, as incubations conducted at $5{ }^{\circ} \mathrm{C}$ grouped above zero, and $13{ }^{\circ} \mathrm{C}$ incubations grouped below (Fig. 4). Microbial community structures in Grane and Troll dispersions were more similar to one another at $13{ }^{\circ} \mathrm{C}$ than at $5{ }^{\circ} \mathrm{C}$
(Fig. 4). From the loadings (Additional file 6: Figure S3), we observed that the major differences of the most important players contribute for different PC2 loadings.

PLS2 analysis of chemistry and microbial community data Correlations between the presence of individual oil compounds and the relative abundance of bacterial families were conducted using multivariate approaches of the two modelled datasets. The results are presented in heatmaps (Figs. 5, 6, 7, 8) and described below.

\section{Biodegradation of dispersed Grane oil at $5{ }^{\circ} \mathrm{C}$}

Biodegradation curves from modelled data and microbial families formed three distinct clusters (Fig. 5). Chemical cluster $1(\mathrm{CC} 1)$ contained parent and alkylated 2- to 3-ring aromatics, long-chain $n$-alkanes, and naphthalenes (C-C4). The persistence of $\mathrm{CC} 1$ compounds correlated negatively (hereinafter "well correlated") with cluster 1 of microbial community (MC1) and indicates a strong correlation between biodegradation and the identified bacterial families. CC2 consisted of complex polyalkylated 2- to 3-ring and 4to 6-ring PAHs and larger n-alkanes, but also isoprenoids. The biodegradation of CC2 compounds also correlated well with MC 1 (blue color, Fig. 5). CC3 consisted of a few 2- to 3 -ring and 4- to 6-ring PAHs and mostly middle-chain $n$-alkanes and its biodegradation correlated most strongly with the MC1 and MC2 (blue color, Fig. 5).

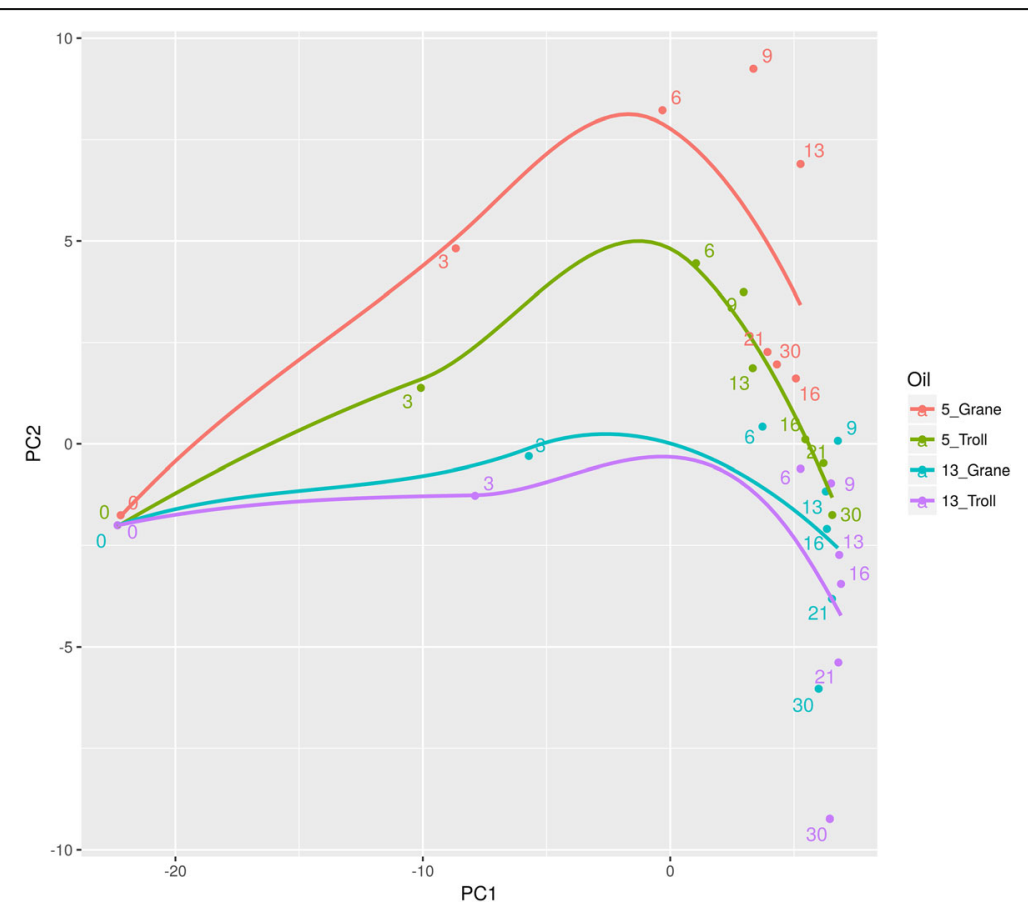

Fig. 4 PCA of the mean relative abundance of bacterial families in each treatment. Flaks contained seawater incubated with chemically dispersed Grane and Troll oil at 13 and $5{ }^{\circ} \mathrm{C}(2-3 \mathrm{mg} / \mathrm{L} ; \mathrm{DOR}$ 1:100). Each treatment is represented as a different colour and the legend details the incubation temperature followed by the oil type. Modelled data are present in the figure alongside experimental data to statically analyse the complete data set. Numbers indicate incubation days. PC1 and PC2 explain 58.2 and $9.5 \%$ of variations, respectively 
Nine bacterial families from MC1 formed a tight subcluster within the main MC1 (NS11.12_marine_group to Alcanivoracaceae) and they all had strong correlations to the biodegradation of complex polyalkylated 2- to 3-ring and 4- to 6-ring PAHs and $n \mathrm{C} 34+$ alkanes within CC2 (Fig. 5). To a lesser extent, this subgroup was also correlated to the biodegradation of isoprenoids and $n \mathrm{C} 29-n \mathrm{C} 33$ alkanes within CC1 (Fig. 5). Kordiimonadaceae, Parvularculaceae and Piscirikettsiaceae from MC1 showed affinity towards CC1 $(R<-0.7)$, in particular naphthalenes, dibenzothiophenes and $n \mathrm{C} 29-n \mathrm{C} 33$ alkanes. In addition, Kordiimonadaceae and Parvularculaceae correlated strongly with $n \mathrm{C} 15-n \mathrm{C} 28$ alkanes $(\mathrm{R}<-0.7)$ from the CC3. Within MC2, Oceanospirillaceae, Helicobacteraceae, Hypomonadaceae and Methylophylaceae correlated $(R<$ - 0.65) with $n \mathrm{C} 15-n \mathrm{C} 28$ from CC3, whereas Methylophylaceae showed also correlation with $\mathrm{CC} 1$ and $\mathrm{CC} 2$ (Fig. 5).

\section{Biodegradation of dispersed troll oil at $5{ }^{\circ} \mathrm{C}$}

Modelled biodegradation curves and the relative abundance of microbial families also formed three distinct clusters in incubations with Troll oil at $5{ }^{\circ} \mathrm{C}$ (Fig. 6). Among the three clusters of degradation curve profiles, CC1 was the tightest cluster and contained 8 complex $\mathrm{C} 2+$ alkylated ( $\mathrm{C} 2$ and greater) 2- to 3-ring $\mathrm{PAH}$ and 4- to 6-ring PAHs and correlated well with MC2 $(R<-0.7)$. Representatives within MC2 were Kordiimonadaceae, Rhodobiaceae, Hypomonadaceae, Oceanospirillales strain SS1.B.06.26, Candidatus Captivus, Aurantimonadaceae and Streptomycetaceae. CC2 consisted of mostly of 2- to 3-ring PAHs and branched alkanes and correlated well with prokaryotes from MC2 and with Piscirikettsiaceae, Rhodothermaceae and Parvulaculaceae from MC3. Interestingly, most of dibenzothiophenes (C1-C3) were located within this $\mathrm{CC} 2$ cluster. Finally, CC3 consists of the whole spectrum of $n$-alkanes and most of naphthalenes (C-C3) and few other 2- to 3-ring PAHs. This cluster correlated well with Oceanospirillaceae $(\mathrm{R}<-0.65)$.

\section{Biodegradation of dispersed Grane oil at $13^{\circ} \mathrm{C}$}

Similar to the other treatments, the biodegradation curves for Grane oil at $13{ }^{\circ} \mathrm{C}$ were also arranged in three clusters (Fig. 7). The first cluster (CC1) contains the whole $n$-alkane spectrum, naphthalenes $(\mathrm{C}-\mathrm{C} 3)$ and the 2- to 3-ring PAHs

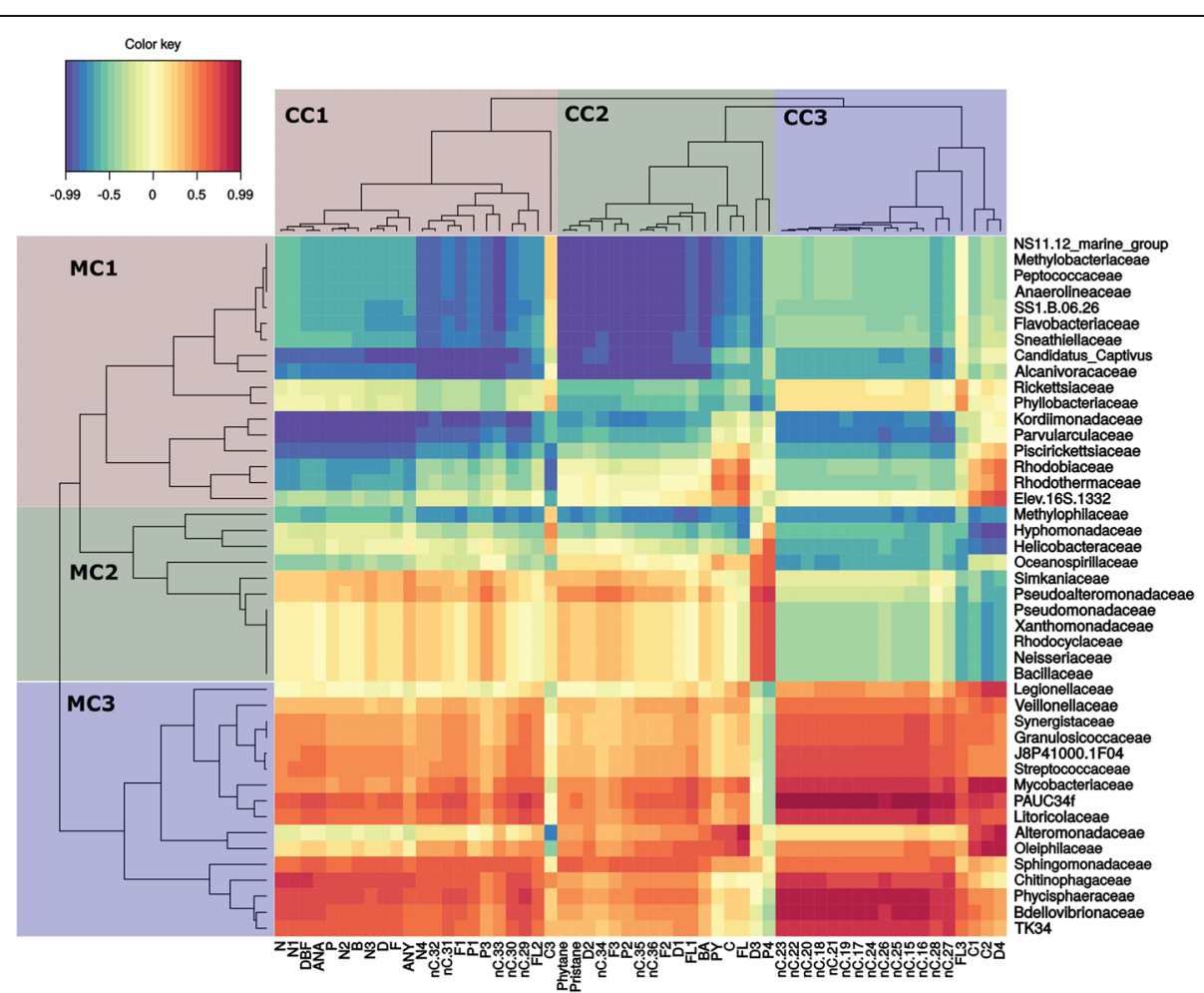

Fig. 5 Grane oil at $5{ }^{\circ} \mathrm{C}$. Heatmap clustering of individual target hydrocarbons based on modelled degradation curves and the mean relative abundance of microbial families. Red color indicates a strong positive correlation between hydrocarbon persistence and bacterial family and thus suggests that biodegradation is not corellated to that family. Blue indicates a strong negative correlation between persistence and bacterial family and thus suggests that biodegradation is corellated to that family. On the left, microbial clusters (MC) are grouped by color and identified as MC1, MC2, or MC3. Single compound clusters (CC) are also grouped by color and identified as CC1, CC2, and CC3. In single compound clusters (CC) n-alkanes are abbreviated by $\mathrm{nC}$. acronym, followed by the number of carbon atoms describing the chain length. Abbreviations for aromatic compounds are further described in additional table (Additional file 3: Table S3) 


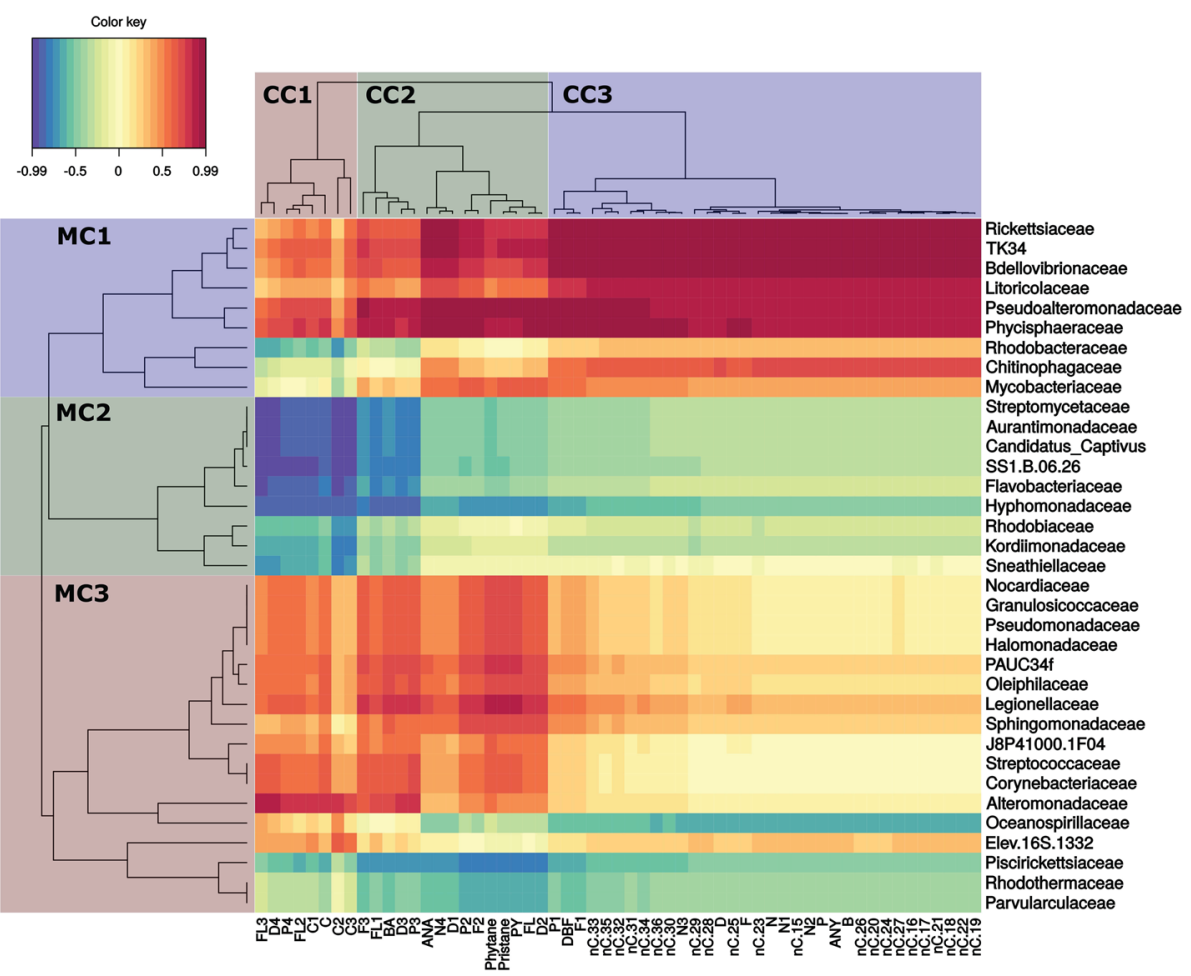

Fig. 6 Troll oil at $5{ }^{\circ} \mathrm{C}$. Heatmap clustering of individual target hydrocarbons based on modelled degradation curves and the mean relative abundance of microbial families. Red color indicates a strong positive correlation between hydrocarbon persistence and bacterial family and thus suggests that biodegradation is not corellated to that family. Blue indicates a strong negative correlation correlation between hydrocarbon persistence and bacterial family and thus suggests that biodegradation is corellated to that family. On the left, microbial clusters (MC) are grouped by color and identified as MC1, MC2, or MC3. Single compound clusters (CC) are also grouped by color and identified as CC1, CC2, and CC3. In single compound clusters (CC) $\mathrm{n}$-alkanes are abbreviated by $\mathrm{nC}$. acronym, followed by the number of carbon atoms describing the chain length. Abbreviations for aromatic compounds are further described in additional table (Additional file 3: Table S3)

(parent and $\mathrm{C} 1$ alkylated). CC1 correlated well $(\mathrm{R}<-0.65)$ with MC2, with the most prominent families being Erythrobacteraceae, Methylophilaceae, Candidatus Captivus and family SS1.B.06.26. Sphingomonadaceae was the only family in $\mathrm{MC} 1$ that exhibited a strong correlation to CC1. CC2 contained $\mathrm{C} 2+$ alkylated 2- to 3-ring PAHs and a few 4- to 6-ring PAHs and isoprenoids. $\mathrm{CC} 2$ had good correlation $(R<-0.7)$ with most representatives from $\mathrm{MC} 2$, but also with Flavobacteriaceae and Kordiimonadaceae from MC1 (Fig. 7). CC3 consisted of mostly polyalkylated 4- to 6-ring PAHs and correlated $(\mathrm{R}<-0.7)$ with Kordiimonadaceae, Phyllobacteriaceae, Flavobacteriaceae, Parvularculaceae, Hypomonadaceae and Litoricolaceae from MC1, and Sneathiellaceae and Rhodobacteraceae from MC2 (Fig. 7).

\section{Biodegradation of dispersed troll oil at $13^{\circ} \mathrm{C}$}

Similar to the Troll oil at $5{ }^{\circ} \mathrm{C}$ and the Grane at both temperatures $\left(13{ }^{\circ} \mathrm{C}\right.$ and $\left.5{ }^{\circ} \mathrm{C}\right)$, three chemical clusters and three microbial clusters were also present in the heatmap for Troll oil at $13{ }^{\circ} \mathrm{C}$. C4 alkylated 2- to 3-ring PAHs and polyalkylated 4- to 6-ring PAHs made up $\mathrm{CC} 1$, which correlated well with most families from MC3 $(\mathrm{R}<-0.7)$ (Fig. 8). CC2 consisted of 2- to 3-ring PAHs and branched alkanes and aligned with a subcluster of MC3 (Alcanivoracaceae to Rhodobacteraceae) and MC1 (Veillonellacae to Oceanospirillales SS1.B.06.26)) $(R<0.7)$. The third chemical cluster (CC3) consisted of the whole spectrum of naphthalenes (C-C4), C-C2 dibenzothiophenes and the whole spectrum of $n$-alkanes. Within MC1, Alteromonadaceae was mostly correlated to the entire CC3, while Flavobacteriaceae and Oceanospirillales strain SS1.B06.26 had a stronger correlation to the alkanes and Colwelliaceae and Oceanospirillaceae had a stronger correlation to the naphthalenes (C-C4), C-C2 dibenzothiophenes. In addition, a small subcluster of MC3 (Erythrobacteraceae, Phyllobacteriaceae and Rhodobacteraceae) also exhibited correlation to the alkanes in CC2.

\section{Differences between oils and temperatures}

Chemical single compound clustering

Four different heatmaps illustrate similarities in biodegradation through the clustering of individual hydrocarbons based on the similarity of slopes of their biodegradation (i.e. decay) curves. In both oils and at both temperatures, the majority of $n$-alkanes and naphthalenes clustered together and clustered apart from 2- to 3-ring and 4- to 6-ring 


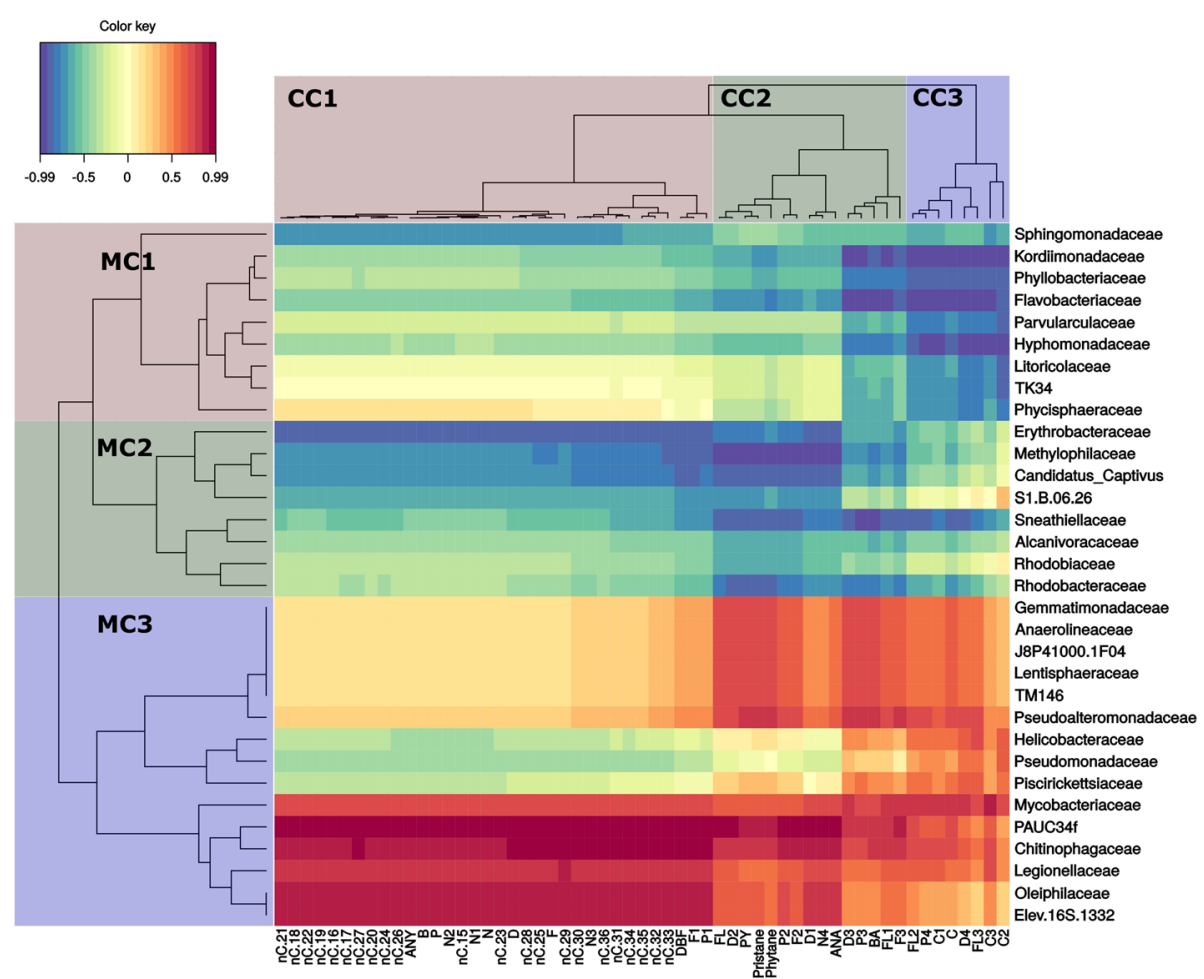

Fig. 7 Grane oil at $13{ }^{\circ} \mathrm{C}$. Heatmap clustering of individual target hydrocarbons based on modelled degradation curves and the mean relative abundance of microbial families. Red color indicates a strong positive correlation between hydrocarbon persistence and bacterial family and thus suggests that biodegradation is not corellated to that family. Blue indicates a strong negative correlation between hydrocarbon persistence and bacterial family and thus suggests that biodegradation is corellated to that family. On the left, microbial clusters (MC) are grouped by color and identified as MC1, MC2, or MC3. Single compound clusters (CC) are also grouped by color and identified as CC1, CC2, and CC3. In single compound clusters (CC) n-alkanes are abbreviated by nC. acronym, followed by the number of carbon atoms describing the chain length. Abbreviations for aromatic compounds are further described in additional table (Additional file 3: Table S3)

PAHs. This clustering was not uniform and varied between oils and temperatures and was dependent on alkylation rate as well as hydrocarbon chain length. Clustering among alkanes exhibited minor differences, but the majority of alkanes clustered in a similar fashion among oil types and temperatures. In the Grane incubation at low temperature $\left(5{ }^{\circ} \mathrm{C}\right)$, higher molecular weight $n$-alkanes were found in $\mathrm{CC} 1$ and $\mathrm{CC} 2$, but the majority of $n$-alkanes were found within CC3 (Fig. 5). In contrast, all alkanes were present in one distinct cluster (CC3) in the Troll incubations at $5{ }^{\circ} \mathrm{C}$ (Fig. 6) and $13^{\circ} \mathrm{C}$ (Fig. 8), as well as the Grane incubation at $13{ }^{\circ} \mathrm{C}$ (Fig. 7). Surprisingly, in Grane incubations at $5{ }^{\circ} \mathrm{C}$, the degradation rates of 4- to 6-ring $\mathrm{PAHs}(\mathrm{CC} 2)$ were more similar to $n$-alkanes $(\mathrm{CC} 3)$ than the degradation rates of 2- to 3-ring PAHs (CC1) (Fig. 5).

The biodegradation of dibenzothiophene was observed for Troll oil, but not for Grane. The chemical formulation of Grane (i.e. low concentration of dibenzothiophene) prevented dibenzothiophene's biodegradation curve to be determined. In seawater incubations with Troll oil at $5{ }^{\circ} \mathrm{C}$, dibenzothiophene was clustered with the 2- to 3-ring PAHs, but at $13{ }^{\circ} \mathrm{C}$ dibenzothiophenes clustered with naphthalenes and $n$-alkanes.

\section{Clustering of microbial families}

Heatmaps did not reveal consistent clustering of microbial families between the oils and temperatures (Figs. 5, 6, 7 and 8). Although, MC1 and MC2 in the incubation with Grane at $13{ }^{\circ} \mathrm{C}$ (Fig. 7) resembled MC3 in the Troll incubation at $13{ }^{\circ} \mathrm{C}$ (Fig. 8) and these clusters were correlated to similar chemical compounds. To some extent, patterns between the two Grane incubations can be seen as MC1 and MC2 contained similar bacterial families at the two different temperatures (Figs. 5 and 7). Nevertheless, there is no clear pattern in clustering of microbial families among oils and temperatures, confirming the differences shown by the PCA output based on microbial community composition (Fig. 4). Overall, Alcanivoracaceae, Candidatus Captivus, Erythrobacteraceae, Flavobacteriaceae, Hyphomonadaceae, Oceanospirillaceae, Rhodobacteraceae, and Oceanospirillales strain SS1.B.06.26 consistently dominated the microbial community, suggesting these 


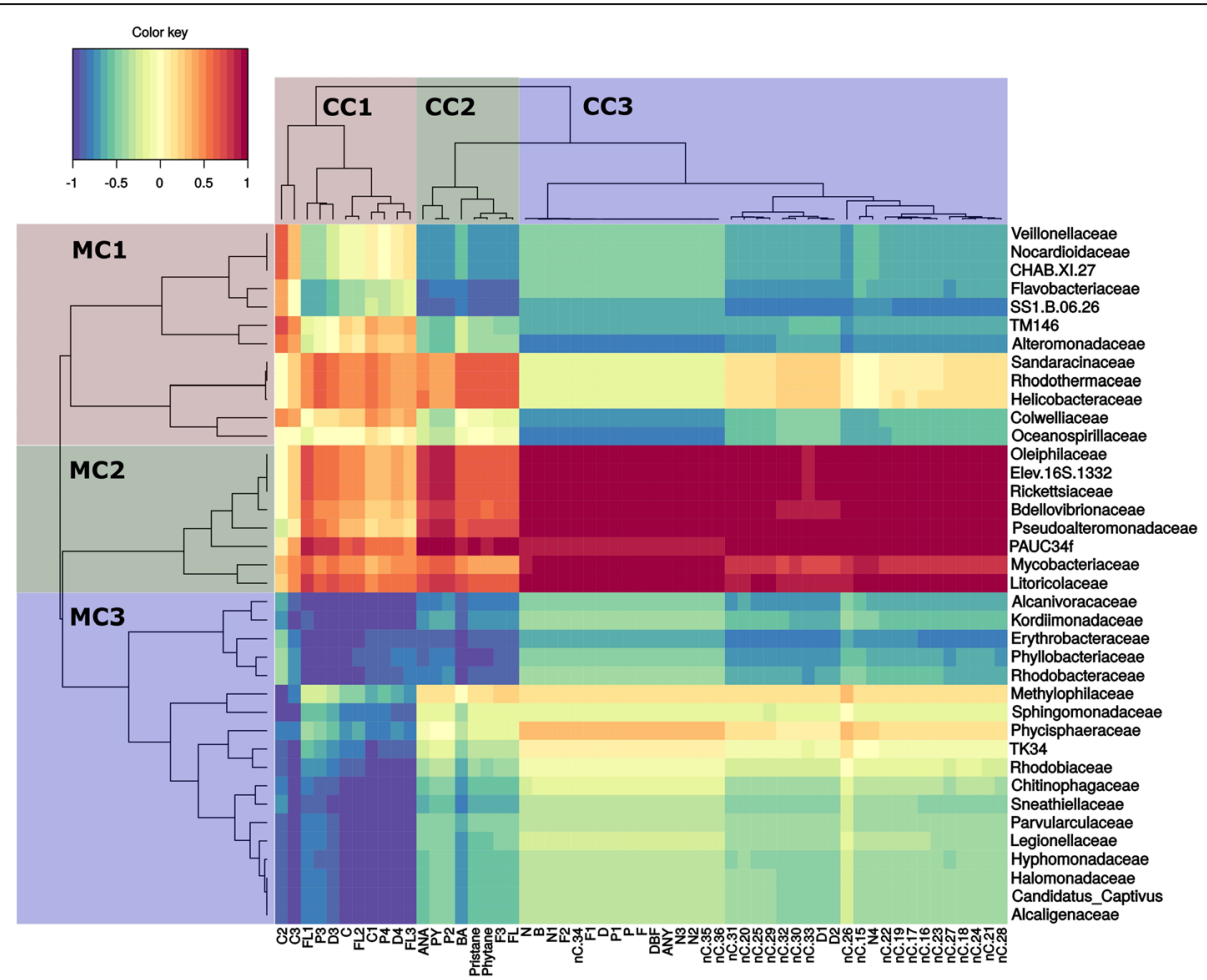

Fig. 8 Troll oil at $13{ }^{\circ} \mathrm{C}$. Heatmap clustering of individual target compounds based on modelled degradation curves and the mean relative abundance microbial families. Red color indicates a strong positive correlation between hydrocarbon persistence and bacterial family and thus suggests that biodegradation is not corellated to that family. Blue indicates a strong negative correlation between hydrocarbon persistence and bacterial family and thus suggests that biodegradation is corellated to that family. On the left, microbial clusters (MC) are grouped by color and identified as MC1, MC2, or MC3. Single compound clusters (CC) are also grouped by color and identified as CC1, CC2, and CC3. In single compound clusters (CC) n-alkanes are abbreviated by nC. acronym, followed by the number of carbon atoms describing the chain length. Abbreviations for aromatic compounds are further described in additional table (Additional file 3: Table S3)

families may be involved in biotransformation of dispersed oil in our incubations.

\section{Discussion}

In this study, we investigated a multivariate approach for the combined analysis of chemistry and microbial data to study the effects of temperature and oil composition on the biodegradation of chemically dispersed oil. Heatmap clustering of modelled microbial community composition did not produce consisting clustering of microbial taxonomic families between the two temperatures and oil types; however, we did observe trends in the relative abundance of specific taxonomic families at different temperatures and oil types. Alcanivoracaceae, Candidatus Captivus, Erythrobacteraceae, Flavobacteriaceae, Hyphomonadaceae, Oceanospirillaceae, Rhodobacteraceae, and Oceanospirillales strain SS1.B.06.26 consistently dominated the microbial community structure, suggesting these families may be involved in the biodegradation of chemically dispersed oil. Clustering of modelled biodegradation curves reveled a strong separation between different oils at the same temperature, indicating that oil composition has a strong effect on biodegradation rates. As expected, temperature produced a substantial effect on the biodegradation pattern of individual alkanes and aromatics, with losses at $13{ }^{\circ} \mathrm{C}$ occurring approximately twice as fast as those at $5{ }^{\circ} \mathrm{C}$. Overall, we found that our modelled chemistry data (Figs. 2, 5, 6, 7 and 8) followed the same trends as our calculated biodegradation rates (Additional file 2: Table S2) and allowed comparison of experiments sampled at different time points.

\section{Biotransformation of dispersed oil}

Soluble low molecular weight compounds (BTEX, phenols, naphthalenes) are usually associated with water accommodated fractions (WAF), while $n \mathrm{C} 6+$ saturates and high molecular weight PAHs are commonly associated with particulate oil. During oil biodegradation, soluble hydrocarbons are generally utilized faster than compounds in the oil phase, as they are easily transported from the water phase into the cell [27]. Interestingly, biodegradation rates of low soluble alkanes have been shown to exceed their respective solubility rates [28], which indicates that oil-degrading bacteria are capable of degrading alkanes in particulate oil. While the 
bioavailability of PAHs is dependent on solubility, the bioavailability of saturates is mainly influenced by physicochemical characteristics of the oil [29].

The PCA plot of chemical profiles compared biodegradation patterns (i.e. PAH/alkane ratio) among the four different incubations and illustrated a similar trajectory among oil types and temperatures (Fig. 2). In addition, when biodegradation patterns at the same time point were compared between incubations, Troll and Grane grouped together at $13{ }^{\circ} \mathrm{C}$ but not at $5{ }^{\circ} \mathrm{C}$; suggesting that biodegradation patterns are more dependent upon temperature than oil type. Low temperatures are known to influence the bioavailability of petroleum hydrocarbons [30], which in turn can affect the type and amount of biodegradation genes expressed by oil-degrading microorganisms. Biodegradation genes were not identified in our incubations, but it is likely that similar biodegradation genes and pathways were expressed [31, 32], with gene expression delayed at the colder temperature. Therefore, oil type and temperature are likely to affect the onset of specific biodegradation pathways by impacting the amount of soluble petroleum hydrocarbons available to oil-degrading microbes.

For both oils, faster transformation rates were observed for $n$-alkanes and aromatics at the higher temperature (Fig. 2; Additional file 1: Table S1). In comparing Troll to Grane at $5{ }^{\circ} \mathrm{C}$, tighter clustering of $n$-alkanes $(n \mathrm{C} 15$ $n$ C36) in Troll was observed (Figs. 5 and 6) and the majority of HMW $n$-alkanes ( $n$ C31 $-n$ C36) had longer half-lives in the Grane incubation (Additional file 1: Table S1). In addition, the more alkylated PAHs also had longer half-lives in the Grane incubation (Additional file 1: Table S1). These results suggest that the bioavailability of HMW saturates and alkylated aromatics were more susceptible to temperature in incubations with Grane oil than Troll. This is supported by the physical characteristics of the two oils. Since Grane is a highly viscous asphaltic crude (Table 1), the bioavailability of compounds associated with particulate oil would be more limited at lower temperatures compared to a lighter oil (e.g. Troll). Surprisingly, alkanes ranging from $n \mathrm{C} 15-n \mathrm{C} 30$ had higher biodegradation half-lives and thus slower biodegradation rates in Troll oil than the more viscous Grane oil at $5{ }^{\circ} \mathrm{C}$ (Additional file 1: Table S1). It is likely that the larger fraction of the light aromatic hydrocarbons of Troll incubation was inhibiting biodegradation. This phenomenon was already observed by RM Atlas [2], where he noticed that light crudes became less degradable at low temperatures compared to heavy crudes. On the other hand, it seems that the bioavailability of long chain $n$-alkanes (nC29+) was decreased in Grane oil compared to Troll based on oil viscosity. This trend in the biotransformation of $n$-alkanes was also observed in clustering, as the decay curves of long chain $n$-alkanes clustered differently between the two oil types at $5{ }^{\circ} \mathrm{C}$ (Figs. 5 and 6) and oils grouped separately before reaching the apex in the bell-shaped curve (Fig. 2).

In addition to temperature dependence in oil biodegradation experiments, clustering based on oil-type and the biodegradation of individual compounds should also be implemented when modelling the fate of oil. For example, the Oil Spill Contingency And Response (OSCAR) model groups compounds based on molecular weight and boiling points, which may overlook the biodegradation of individual compounds. Therefore, there is need to refine such an approach, as compounds may not follow biotransformation patterns based solely on these conditions.

\section{Microbial community dynamics}

Modelled microbial community datasets revealed differences between the two temperatures and oils, especially at low temperature. Throughout the incubation, microbial community structure in Troll and Grane incubations appeared more similar at $13{ }^{\circ} \mathrm{C}$ than at $5{ }^{\circ} \mathrm{C}$. At the end of the incubation, the microbial community in incubations with Troll at $5{ }^{\circ} \mathrm{C}$ was more similar to communities present at $13{ }^{\circ} \mathrm{C}$ in both Troll and Grane incubations than to communities exposed to Grane oil at $5{ }^{\circ} \mathrm{C}$ (Fig. 4). Principal oil-degraders observed in this study are well known hydrocarbon biodegrading microbes observed in a variety of studies following the Deepwater Horizon (DWH) spill. Oceanospirillaceae, which was one of the initial families to increase in our incubations at both temperatures, was also detected in the DWH as a principal microorganism for $n$-alkane degradation [33, 34]. Colwelliaceae, on the other hand, was associated with the biodegradation of both $n$-alkanes and aromatics [33, 35]. In both oils, Colwelliaceae and Oceanospirillaceae were more prominent in colder $\left(5{ }^{\circ} \mathrm{C}\right)$ than warmer $\left(13{ }^{\circ} \mathrm{C}\right)$ incubation (Fig. 3). Oleispira (a genus of Oceanospirillaceae) and Colwellia (a genus of Colwelliaceae) are commonly found in Arctic environments in response to oil [36, 37]. Piscirickettsiaceae were active in our study at both temperatures, preferring Troll oil to Grane oil, and were also enriched in the deepsea plume of dispersed oil during the DWH [33]. Flavobacteriaceae, Rhodobacteraceae and Alteromonadaceae also increased in abundance during the DWH after Oceanospirillaceae and Colwelliaceae peaked, suggesting that members of these microbial families may consume biodegradation metabolites [33, 38, 39].

The approach of presenting the most abundant taxa is a common practice as they are usually the most influential; however, highly abundant taxa may overshadow the role of low abundant species in biodegradation. Biodegradation occurs throughout the community and rare taxa may be more important than previously thought 
[40]. By correlating the modelled data in cluster heatmaps (Figs. 5, 6, 7 and 8), we were able to screen for individual microbes that may have played a key role in the loss of individual hydrocarbons. Some bacterial families correlated $(R<-0,65)$ with the loss of targeted analytes and were also found in literature to be involved directly or indirectly in biodegradation processes of hydrocarbons. Flavobacteriaceae, Oceanospirillaceae, Piscirickettsiaceae and Rhodobacteraceae include known oil-degrading microbes and were identified as the most abundant families in our incubations, but other taxa known to include oil-degrading microbes were also found in our incubations, but at a low abundance $(<1 \%)$ (e.g. Alcanivoracaceae, Methylophilaceae, Sphingomonadaceae and Erythrobacteraceae) [41-44].

Our data show that oil-degraders do not correlate perfectly with the biodegradation of individual hydrocarbons (e.g., Oceanospirillaceae in Grane at $13{ }^{\circ} \mathrm{C}$, or Piscirickettsiaceae in Troll and Grane at $13{ }^{\circ} \mathrm{C}$ ). One of the reason for this discrepancy may be that microbes need to increase in abundance prior to significant depletion of hydrocompounds. Therefore, a natural lag may exist between increases in relative abundances of specific taxa and the chemical loss of individual compounds. In addition, since oil degrading genes are so ubiquitous, there are likely many other taxa that are contributing to oil loss than just the most abundant microbes. Hence, it is important to note that the correlation does not imply causality, and drawing conclusions only based on correlation outcomes should be considered a poor practice.

Given the relatively few data points collected in this study, a full-scale time series analysis of the data was not pursued. Future studies should pursue analyses at a higher time-resolution, as this would expand the options for time-series analysis tools for microbial data. These possibilities have been excellently summarized by $\mathrm{K}$ Faust, L Lahti, D Gonze, WM de Vos and J Raes [45], where most methods are judged carefully as to not infer causal connections.

\section{Conclusions}

In the current paper, our aim was to introduce a different approach for evaluating and presenting complex microbial and chemical datasets for oil biodegradation incubation experiments. As opposed to multiple univariate analysis usually applied to microbial and chemical analyses, we present here a multivariate approach of connecting microbial community and chemical datasets. Using samples obtained from different incubations at different time points, this multivariate approach allowed us to evaluate how different temperatures and oil types influence modelled biodegradation processes, including single compound depletion and changes in microbial community composition at specific time points. As expected, temperature was shown to have a strong effect on biodegradation efficiency and community dynamics. These results suggest that different oil types may influence degradation rates and microbial community structure, especially at low temperatures $\left(5{ }^{\circ} \mathrm{C}\right)$. Finally, correlation of microbial taxa with individual hydrocarbons revealed the potential influence of low-abundant taxa on oil biodegradation in marine environments.

\section{Additional file}

Additional file 1: Table S1. Experimental design. Sampling days and number of replicates are described for all experimental analyses. The following coding system is applied: $X+Y+Z$, where $X$ is number of replicates for oil dispersions in natural unfiltered seawater, $Y$ is number of replicates for dispersions in sterilized filtered seawater, and $Z$ is number of replicates for natural unfiltered seawater without oil. (PDF 391 kb)

Additional file 2: Table S2. Calculated half-lives for targeted oil compounds. (PDF $72 \mathrm{~kb}$ )

Additional file 3: Table S3. List of abbreviations for aromatics compounds used in correlation plots. (PDF $40 \mathrm{~kb}$ )

Additional file 4: Figure S1. Microbial community composition in control samples over the incubation period. (PDF $103 \mathrm{~kb}$ )

Additional file 5: Figure S2. Biotransformation of targeted semivolatile n-alkanes (A and B) and PAH (C and D) in dispersions of Troll and Grane oils at $13^{\circ} \mathrm{C}$ and $5^{\circ} \mathrm{C}$. (PDF $195 \mathrm{~kb}$ )

Additional file 6: Figure S3. PC2 loadings for PCA analysis of microbial community dynamics (Fig. 4). Only top 30 loadings and corresponding taxa are presented here for readability. (PDF $48 \mathrm{~kb}$ )

\section{Abbreviations}

BTEX: Benzene, toluene, ethylbenzene, xylen; CC: Chemical cluster; DCM: Dichloromethane; DOR: Dispersant to oil ratio; DWH: Deepwater Horizon; FID: Flame ionization detector; GC: Gas chromatography; LOD: Limit of detection; MC: Microbial cluster; MS: Mass spectometry; OTU: Operational taxonomic unit; PAH: Polycyclic aromatic hydrocarbons; PCA: Principal components analysis; TEOC: Total extractable organic carbon; WAF: Water accomodated fraction

\section{Acknowledgements}

We would like to thank the staff at the SINTEF Ocean SeaLab for performing the chemical analyses (Marianne Rønsberg, Kjersti Amås and Inger Steinsvik).

\section{Funding}

This study is a part of a project which is funded by The Research Council of Norway (project \# 22827/E30: Oil Spill Dispersant Strategies and Biodegradation Efficiency) and the oil companies Statoil ASA, AkerBP ASA, ExxonMobil Production Norway Inc., Total E\&P and ConocoPhillips Skandinavia AS.

\section{Availability of data and materials}

Nucleotide sequence data for 16S rRNA amplicon sequences were deposited to the European Nucleotide archive (ENA) as a study entitled "PETROMAKS E\#9", with accession code PRJEB24201.

\section{Authors' contributions}

$\mathrm{OGB}, \mathrm{RN}$ and DR designed and carried out the experimental work. AW prepared samples for sequencing and conducted NGS. TRS, OGB and DR conducted analytical work. TRS, DR and KMF wrote the manuscript with input from OGB, RN, AW and MTH. All authors read and approved the final manuscript.

Ethics approval and consent to participate Not applicable. 


\section{Consent for publication}

Not applicable.

\section{Competing interests}

Authors declare that they have no competing interests.

\section{Publisher's Note}

Springer Nature remains neutral with regard to jurisdictional claims in published maps and institutional affiliations.

\section{Author details}

${ }^{1}$ SINTEF Ocean, Environment and New Resources, Brattørkaia 17C, 7010 Trondheim, Norway. ${ }^{2}$ Department Clinical and Molecular Medicine, The Norwegian University of Science and Technology, 7491 Trondheim, Norway. ${ }^{3}$ Bielefeld University, Center for Biotechnology (CeBiTec), 33501 Bielefeld, Germany.

\section{Received: 21 February 2018 Accepted: 10 July 2018}

Published online: 07 August 2018

\section{References}

1. Arrhenius S. Über die Reaktionsgeschwindigkeit bei der Inversion von Rohrzucker durch Säuren. Z Phys Chem. 1889;4U, 226

2. Atlas RM. Effects of temperature and crude oil composition on petroleum biodegradation. Appl Microbiol. 1975:30(3):396-403.

3. Leahy JG, Colwell RR. Microbial degradation of hydrocarbons in the environment. Microbiol Rev. 1990;54(3):305-15.

4. D'Amico S, Collins T, Marx J-C, Feller G, Gerday C. Psychrophilic microorganisms: challenges for life. EMBO Rep. 2006;7(4):385-9.

5. Bentahir M, Feller G, Aittaleb M, Lamotte-Brasseur J, Himri T, Chessa JP, Gerday C. Structural, kinetic, and calorimetric characterization of the coldactive phosphoglycerate kinase from the antarctic Pseudomonas sp. TACI118. J Biol Chem. 2000;275(15):11147-53.

6. Redmond MC, Valentine DL. Natural gas and temperature structured microbial community response to the Deepwater horizon oil spill. Proc Natl Acad Sci. 2012:109(50):20292-7.

7. McFarlin KM, Questel JM, Hopcroft RR, Leigh MB. Bacterial community structure and functional potential in the northeastern Chukchi Sea. Cont Shelf Res. 2017;136:20-8

8. Hazen TC, Dubinsky EA, DeSantis TZ, Andersen GL, Piceno YM, Singh N, Jansson JK, Probst A, Borglin SE, Fortney JL et al: Deep-Sea oil plume enriches indigenous oil-degrading Bacteria. Science 2010, 330(6001):204-208.

9. Faksness L-G, Brandvik PJ, Sydnes LK. Composition of the wate accommodated fractions as a function of exposure times and temperatures. Mar Pollut Bull. 2008;56(10):1746-54.

10. Hughey R, Karplus K. Bioinformatics: a new field in engineering education. J Eng Educ. 2003;92(1):101-4.

11. Reed M, Aamo OM, Daling PS. Quantitative analysis of alternate oil spill response strategies using OSCAR. Spill Science \& Technology Bulletin. 1995;2(1):67-74.

12. Peck JE. Multivariate analysis for community ecologists : step-by-step using PC-ORD. Gleneden Beach, Or: MjM software design; 2010.

13. Brakstad OG, Throne-Holst M, Nordtug T. Oil droplet generation and incubation for biodegradation studies of dispersed oil. In: McGenity TJ, Timmis KN, Berlin NB, editors. Hydrocarbon and lipid microbiology protocols: pollution mitigation and waste treatment applications. Heidelberg: Springer Berlin Heidelberg; 2017. p. 237-53.

14. Brakstad OG, Nordtug T, Throne-Holst M: Biodegradation of dispersed Macondo oil in seawater at low temperature and different oil droplet sizes. Mar Pollut Bull 2015, 93(1-2):144-152.

15. Prince RC, McFarlin KM, Butler JD, Febbo EJ, Wang FCY, Nedwed TJ. The primary biodegradation of dispersed crude oil in the sea. Chemosphere. 2013;90(2):521-6

16. Brakstad OG, Daling PS, Faksness L-G, Almås IK, Vang S-H, Syslak L, Leirvik F. Depletion and biodegradation of hydrocarbons in dispersions and emulsions of the Macondo 252 oil generated in an oil-on-seawater mesocosm flume basin. Mar Pollut Bull. 2014;84(1-2):125-34.

17. Prince RC, Elmendorf DL, Lute JR, Hsu CS, Haith CE, Senius JD, Dechert GJ, Douglas GS, Butler EL. 17.Alpha.(H)-21.Beta.(H)-hopane as a conserved internal marker for estimating the biodegradation of crude oil. Environmental Science \& Technology. 1994;28(1):142-5.
18. Wang Z, Fingas M, Blenkinsopp S, Sergy G, Landriault M, Sigouin L, Foght J, Semple K, Westlake DWS. Comparison of oil composition changes due to biodegradation and physical weathering in different oils. J Chromatogr A. 1998;809(1):89-107.

19. Klindworth A, Pruesse E, Schweer T, Peplies J, Quast C, Horn M, Glockner FO Evaluation of general 165 ribosomal RNA gene PCR primers for classical and next-generation sequencing-based diversity studies. Nucleic Acids Res. 2013; 41(1):e1.

20. Caporaso JG, Kuczynski J, Stombaugh J, Bittinger K, Bushman FD, Costello EK, Fierer N, Pena AG, Goodrich JK, Gordon Jl et al: QIIME allows analysis of high-throughput community sequencing data. Nat Meth 2010, 7(5):335-336

21. Edgar RC, Haas BJ, Clemente JC, Quince C, Knight R. UCHIME improves sensitivity and speed of chimera detection. Bioinformatics. 2011;27(16): 2194-200.

22. Edgar RC. Search and clustering orders of magnitude faster than BLAST. Bioinformatics. 2010;26(19):2460-1.

23. Caporaso JG, Bittinger K, Bushman FD, DeSantis TZ, Andersen GL, Knight R. PyNAST: a flexible tool for aligning sequences to a template alignment. Bioinformatics. 2010;26(2):266-7.

24. Wang Q, Garrity GM, Tiedje JM, Cole JR. Naïve Bayesian classifier for rapid assignment of rRNA sequences into the new bacterial taxonomy. Appl Environ Microbiol. 2007;73(16):5261-7.

25. McMurdie PJ, Holmes S. Phyloseq: an R package for reproducible interactive analysis and graphics of microbiome census data. PLoS One. 2013;8(4): e61217.

26. Lê Cao K-A, Costello M-E, Lakis VA, Bartolo F, Chua X-Y, Brazeilles R, Rondeau $P$. MixMC: a multivariate statistical framework to gain insight into microbial communities. PLoS One. 2016:11(8):e0160169.

27. Hua F, Wang HQ. Uptake and trans-membrane transport of petroleum hydrocarbons by microorganisms. Biotechnol Biotechnol Equip. 2014;28(2): 165-75.

28. Huesemann MH, Hausmann TS, Fortman TJ. Does bioavailability limit biodegradation? A comparison of hydrocarbon biodegradation and desorption rates in aged soils. Biodegradation. 2004;15(4):261-74.

29. Brakstad OG, Booth AM, Faksness LG, Aislabe J. Microbial degradation of petroleum compounds in cold marine water and sea ice. In: Bej AK, Atlas RM, editors. Polar microbiology: the ecology, biodiversity and bioremediation potential of microorganisms in extremely cold environments. New York: CRC Press; 2009. p. 231-53.

30. Bagi A, Pampanin DM, Brakstad OG, Kommedal R. Estimation of hydrocarbon biodegradation rates in marine environments: a critical review of the Q10 approach. Mar Environ Res. 2013;89(Supplement C):83-90.

31. Pérez-Pantoja D, González B, Pieper DH. Aerobic Degradation of Aromatic Hydrocarbons. In: Rojo F, editor. Aerobic Utilization of Hydrocarbons, Oils and Lipids. Cham: Springer International Publishing; 2016. p. 1-44.

32. Rojo F. Enzymes for aerobic degradation of alkanes. In: Timmis KN, editor. Handbook of hydrocarbon and lipid microbiology. Berlin, Heidelberg: Springer Berlin Heidelberg; 2010. p. 781-97.

33. Dubinsky EA, Conrad ME, Chakraborty R, Bill M, Borglin SE, Hollibaugh JT, Mason OU, M. Piceno Y, Reid FC, Stringfellow WT, et al. Succession of hydrocarbon-degrading Bacteria in the aftermath of the Deepwater horizon oil spill in the Gulf of Mexico. Environ Sci Technol. 2013;47(19):10860-7.

34. Mason OU, Hazen TC, Borglin S, Chain PSG, Dubinsky EA, Fortney JL, Han J, Holman H-YN, Hultman J, Lamendella R et al: Metagenome, metatranscriptome and single-cell sequencing reveal microbial response to Deepwater horizon oil spill. ISME J 2012, 6(9):1715-1727.

35. Mason OU, Han J, Woyke T, Jansson JK. Single-cell genomics reveals features of a Colwellia species that was dominant during the Deepwater horizon oil spill. Front Microbiol. 2014;5(332):332

36. Deppe U, Richnow H-H, Michaelis W, Antranikian G. Degradation of crude oil by an arctic microbial consortium. Extremophiles. 2005;9(6):461-70.

37. Yakimov MM, Timmis KN, Golyshin PN. Obligate oil-degrading marine bacteria. Curr Opin Biotechnol. 2007;18(3):257-66.

38. Bælum J, Borglin S, Chakraborty R, Fortney JL, Lamendella R, Mason OU, Auer M, Zemla M, Bill M, Conrad ME et al. Deep-sea bacteria enriched by oil and dispersant from the Deepwater horizon spill. Environ Microbiol 2012, 14(9):2405-16

39. Yang T, Nigro LM, Gutierrez T, D Ambrosio L, Joye SB, Highsmith $R$, Teske A: Pulsed blooms and persistent oil-degrading bacterial populations in the water column during and after the Deepwater Horizon blowout. Deep Sea Res Part II: Topical Studies in Oceanography. 2016;129:282-91. 
40. Huber JA, Mark Welch DB, Morrison HG, Huse SM, Neal PR, Butterfield DA, Sogin ML. Microbial population structures in the deep marine biosphere. Science. 2007;318(5847):97-100.

41. Wang H, Wang B, Dong W, Hu X. Co-acclimation of bacterial communities under stresses of hydrocarbons with different structures. Sci Rep. 2016;6: 34588.

42. Redmond MC, Valentine DL, Sessions AL. Identification of novel methane-, ethane-, and propane-oxidizing Bacteria at marine hydrocarbon seeps by stable isotope probing. Appl Environ Microbiol. 2010;76(19):6412-22.

43. Ghosal D, Ghosh S, Dutta TK, Ahn Y. Current state of knowledge in microbial degradation of polycyclic aromatic hydrocarbons (PAHs): a review. Front Microbiol. 2016;7:1369.

44. Yakimov MM, Golyshin PN, Lang S, Moore ER, Abraham WR, Lunsdorf $H$, Timmis KN. Alcanivorax borkumensis gen. Nov., sp. nov., a new, hydrocarbon-degrading and surfactant-producing marine bacterium. Int $\rfloor$ Syst Bacteriol. 1998;48(Pt 2):339-48.

45. Faust K, Lahti L, Gonze D, de Vos WM, Raes J. Metagenomics meets time series analysis: unraveling microbial community dynamics. Curr Opin Microbiol. 2015;25(Supplement C):56-66.

Ready to submit your research? Choose BMC and benefit from:

- fast, convenient online submission

- thorough peer review by experienced researchers in your field

- rapid publication on acceptance

- support for research data, including large and complex data types

- gold Open Access which fosters wider collaboration and increased citations

- maximum visibility for your research: over $100 \mathrm{M}$ website views per year

At $\mathrm{BMC}$, research is always in progress.

Learn more biomedcentral.com/submissions 